Published in final edited form as:

Patient Educ Couns. 2013 November ; 93(2): 306-311. doi:10.1016/j.pec.2013.06.030.

\title{
What patients think doctors know: Beliefs about provider knowledge as barriers to safe medication use
}

\author{
Marina Serpera,b, ${ }^{\text {, }}$, Danielle M. McCarthy ${ }^{c}$, Rachel E. Patzerd, Jennifer P. King ${ }^{\mathrm{a}}$, Stacy C. \\ Bailey $^{\mathrm{e}}$, Samuel G. Smith ${ }^{\dagger}$, Ruth M. Parker ${ }^{\mathrm{g}}$, Terry C. Davis ${ }^{\mathrm{h}}$, Daniela P. Ladner ${ }^{\mathrm{b}}$, and \\ Michael S. Wolf ${ }^{a, b, i}$ \\ ${ }^{a}$ Health Literacy and Learning Program, Division of General Internal Medicine, Northwestern \\ University, Feinberg School of Medicine, Chicago, USA \\ b Northwestern University Transplant Outcomes Research Collaborative (NUTORC), \\ Comprehensive Transplant Center (CTC), Northwestern University Feinberg School of Medicine, \\ Chicago, USA \\ c Department of Emergency Medicine, Northwestern University Feinberg School of Medicine, \\ Chicago, USA \\ d Division of Transplantation, Department of Surgery, Emory University School of Medicine, \\ Atlanta, USA \\ e Division of Pharmaceutical Outcomes and Policy, University of North Carolina Eshelman School \\ of Pharmacy, Chapel Hill, USA \\ ${ }^{f}$ Health Behaviour Research Centre, Department of Psychology, University College, London, \\ United Kingdom \\ 9 Division of General Medicine, Emory University School of Medicine, Atlanta, USA \\ h Department of Medicine-Pediatrics, Louisiana State University Health Sciences Center, \\ Shreveport, USA \\ i Department of Learning Sciences, School of Education and Social Policy, Northwestern \\ University, Evanston, USA
}

\begin{abstract}
Objective-We examined patient beliefs about provider awareness of medication use, patientreported prevalence and nature of provider counseling about medications, and the impact of health literacy on these outcomes.

Methods-Structured interviews were conducted at academic general internal medicine clinics and federally qualified health centers with 500 adult patients. Interviewer-administered surveys
\end{abstract}

(C) 2013 Elsevier Ireland Ltd. All rights reserved.

*Corresponding author at: Health Literacy and Learning Program, Northwestern University Transplant Outcomes Research Center (NUTORC), Feinberg School of Medicine, Northwestern University, 750 N. Lake Shore Drive, 10th Floor, Chicago, IL 60611, USA. Tel.: +1 312503 5592; fax: +1 312503 2777. marina-serper@fsm.northwestern.edu, mserper@gmail.com (M. Serper)..

Conflict of interest

No financial disclosures were reported by the authors of this paper. 
assessed patients' beliefs, self-reported prevalence and nature of provider counseling for new prescriptions, and medication review.

Results-Most patients believed their physician was aware of all their prescription and over the counter medications, and all medications prescribed by other doctors; while a minority reported disclosing over the counter and supplement use. Among those receiving new prescriptions $(n=$ 190): $51.3 \%$ reported physician medication review, $77.4 \%$ reported receiving instructions on use from physicians and $43.3 \%$ from pharmacists. Side effects were discussed $42.9 \%$ of the time by physicians and $25.8 \%$ by pharmacists. Significant differences in outcomes were observed by health literacy, age, and clinic type.

Conclusions-There is a sizable gap between what patients believe physicians know about their medication regimen and what they report to the physician.

Practice implications-Discordance between patient beliefs and physician knowledge of medication regimens could negatively impact patient safety and healthcare quality.

\section{Keywords}

Patient beliefs; Patient provider communication; Medications; Health literacy; Medication; Safety

\section{Introduction}

For half of US adults, taking prescription medications is a daily activity that must be sustained over time to treat one or more chronic conditions [1-3]. Multiple studies and seminal reports from the Institute of Medicine (IOM) have identified that medication nonadherence (intentional or unintentional) leads to increased cost, morbidity, and mortality [47]. Patients with low health literacy and older adults are among the most vulnerable; with high rates of misunderstanding of medication instructions and warning labels leading to unintentional non-adherence and adverse events [5,8-13]. Medical providers play an integral role in educating patients to promote safe medication use; however, appropriate counseling relies on the patients' disclosure of: (1) medications prescribed by other physicians; (2) nonprescription drugs and supplements; and (3) medications filled by pharmacies that are not electronically linked to the primary care practice.

Previous studies have found deficiencies in patient-provider communication with patients failing to report medications prescribed by other practitioners, discuss medication concerns, and disclose the use of non-prescribed and complementary therapies [12,14-18]. The quality and quantity of physician counseling on appropriate medication use are highly variable; physicians often fail to speak with patients about the importance of adherence or to address any patient concerns about medication side effects or cost [12,15,18-21]. Pharmacist engagement with patients about medications is also suboptimal [22]. Despite the federal mandate for drug counseling at the point of prescribing, multiple studies suggest that direct pharmacist counseling does not routinely occur in the community [23-28]. The lack of uniform integration between medical practices and community retail pharmacies serves as an additional barrier to maintaining an accurate medication record [29-31]. Additionally, the recent dramatic increase in patient use of internet pharmacies, many of which do not require 
a legitimate prescription, do not allow providers the opportunity to ensure safe practices by counseling and may further contribute to patients' lack of disclosure $[32,33]$.

It is unclear whether differences in patients' perceptions from providers' perceptions may contribute to inadequate communication about medications. Previous studies examining patient beliefs about medications have been small, largely descriptive and have yielded contradictory results [18]. No published studies to date have examined patient beliefs about provider knowledge and awareness of medications. Additionally, the effect of the electronic health record (EHR) and electronic prescribing on patient beliefs and patient-provider communication are not well-established.

The purpose of this study was to examine patient beliefs about provider knowledge of medications and also related patient-provider communication. We performed crosssectional, structured interviews with patients seeking care at primary care clinics to assess: (1) patient beliefs of physician awareness of their entire medication regimen and (2) patientreported rates of medication list review, counseling on use, and discussion of side effects by physicians and pharmacists. We also performed exploratory analyses to assess whether the presence of the electronic health (EHR) may affect patient-provider communication.

\section{Methods}

\subsection{Study participants}

Adult patients who attended one of four outpatient primary care clinics were recruited in Shreveport, Louisiana and Chicago, Illinois. One clinic in each city was an academic general medicine practice while a second clinic was a safety-net community health center. Subject recruitment and interviews took place between June and August 2007. Patients were considered eligible if they were 18 or older and ineligible if the clinic nurse or study research assistant identified a patient as having one or more of the following: (1) severely impaired vision; (2) hearing problems; (3) illness severe enough to preclude participation in the survey; and (4) limited English proficiency. Verbal informed consent for the study was obtained by the research assistants by approaching the patients in the clinic. Institutional Review Boards for all locations approved the study.

A total of 562 patients were approached in the order that they arrived at the clinics prior to the medical encounter; 530 consented to the study. Thirteen patients were excluded based on self-reported hearing $(n=3)$ or vision $(n=10)$ impairments. Ten patients were excluded due to limited English proficiency and seven were excluded based on incomplete information, resulting in a sample size of 500 patients. The sample was evenly split across the two geographic locations ( $n=250$ per city) and practice setting (academic, safety net; $n=125$ within each study location). A response rate was determined following the American Association for Public Opinion Research standards, estimating that $92.8 \%$ of approached eligible patients participated in the study [34].

\subsection{Procedure and measurement}

Structured interviews were conducted with all patients to assess beliefs about provider knowledge of their medication regimen. Three items using a 4-point Likert scale set of 
response options assessed patients' perceptions about their physician's understanding of their medication use ('my doctor is aware of all of the medicines that I am taking', 'my doctor is aware of all of the over-the-counter drugs (OTC) that I am taking', 'my doctor is aware of all of the medicines that other doctors prescribe me'). In addition, we asked patients whether or not they told their doctor about the use of OTC drugs, herbal supplements or vitamins.

Participants were then asked if they had received a new prescription medication from their doctor within the past three months. A total of 190 of the 500 patients (38.0\%) stated they had received a new prescription; these individuals were asked additional items to assess the prevalence of: (1) physician-patient communication pertaining to the use of a new prescription medication ('did your doctor explain to you how to take this medicine', 'did your doctor teach you about any potential side effects or risks'); (2) pharmacist-patient communication pertaining to the use of a new prescription medication (modified from above). A trained research assistant administered the interview that included self-report of socio-demographic information (age, gender, race, education) and the number of daily prescription medications currently taken. The Rapid Estimate of Adult Literacy in Medicine (REALM) was used to assess participant literacy skills [35].

\subsection{Analysis plan}

Descriptive statistics (percentage, mean and standard deviation) were calculated for each variable. Responses to items assessing patient beliefs and self-reported provider-patient communication were dichotomized based on valence (strongly or slightly agree vs. strongly or slightly disagree). Chi-square tests were used to evaluate the association between sample characteristics and item responses. Multivariable logistic regression models were performed for each belief and communication outcome, including any variables found in bivariate analyses to be significant at $p<0.10$ as covariates. All statistical analyses were performed using STATA software version 10.0 (StataCorp, College Station, TX, USA).

\section{Results}

Table 1 provides a socio-demographic and clinical profile for both the total patient sample $(n=500)$ and the subsample of those patients receiving a new prescription in the past three months $(n=190)$. In general, patients were middle-aged, predominantly female $(60.4 \%)$, and black (63.6\%). About half (52.6\%) reported a high school level of education or less and half (52.5\%) had limited literacy skills. One quarter (23.0\%) of patients had two or more prescribing physicians, with an average number of 2.9 prescriptions (range: $0-27)$. Few differences were noted among those receiving new prescriptions $(n=190)$, with exceptions being the number of prescribing physicians and prescriptions currently taken. In addition, more patients in the safety-net clinic sites received a new prescription in the past three months compared to those in the academic setting ( $64.9 \%$ vs. $35.1 \%, p<0.001)$.

The majority of patients believed that their physician was aware of all prescription and OTC medications they were currently taking $(90.2 \%$ and $85.4 \%$ respectively; Table 2$)$.

Additionally, most patients believed that doctors were aware of medications that were prescribed by other doctors (91.3\%). However, less than half of participants reported having told their doctor about any OTC drugs (46.0\%), herbal supplements or vitamins (34.1\%). 
Patients with a higher number of prescribing physicians and daily medications, and patients who received care at academic practices were significantly more likely to believe that their doctor was aware of their entire medication regimen, including drugs prescribed by other providers (Table 3). Factors associated with higher rates of disclosure of non-prescribed medications (OTC drugs, herbal supplements, vitamins) were: a higher number of prescribing physicians, higher number of daily medications, receiving care at an academic medical center, older age, and non-black race. Factors associated with lower rates of disclosure were: fewer years of formal education, lower literacy, and black race $(p<0.05$ for each association).

Among only those participants who received a new prescription in the past three months ( $n$ $=190)$, half $(51.3 \%)$ reported that their doctor reviewed the medication list with them. Most (77.4\%) reported that their doctor explained how to take the medication, while less than half received instructions on proper medication use from their pharmacist (43.3\%; Table 2). Side effects were less often discussed by both physicians (42.9\%) and pharmacists (25.8\%). According to patient self-report, older patients were significantly more likely to have the doctor review their medication list, but were significantly less likely to receive information on side effects (Table 4). Patients who were taking more daily medications and receiving care at academic practices were more likely to report that physicians explained how to take medications and reviewed the medication list.

Based on noted clinic differences (academic vs. safety net), we performed exploratory analyses to further understand these associations. Only one of the sites (the academic site in Chicago) utilized an electronic health record (EHR) with computerized order entry and electronic prescribing capabilities; the other academic site and both safety net clinics used paper charts. Patients at the EHR location $(n=65)$ were more likely to believe their doctor was aware of all medicines they were taking $(97.6 \%$ vs. $87.7 \%, p=0.001)$, all OTC drugs and supplements they were taking $(91.7 \%$ vs. $83.4 \%, p=0.03)$, and prescriptions from other physicians $(95.8 \%$ vs. $89.8 \%, p=0.04)$. Patients who received a new prescription from the EHR-equipped site were significantly more likely to report that their doctor talked to them about how to take their medicine $(90.8 \%$ vs. $70.4 \%, p<0.001)$, and review their current medication list $(78.9 \%$ vs. $42.3 \%, p<0.001)$.

In multivariable regression analysis, females (Adjusted Odds Ratio (OR) 2.8, 95\% Confidence Interval (CI) $1.5-5.6, p=0.002$ ) were significantly more likely than males to believe their primary care doctor knew about all medications prescribed by other physicians. Compared to patients at academic health centers, patients receiving care at safety-net clinics were less likely to believe their doctor knew of all the medications they were currently taking (OR 0.2, 95\% CI 0.1-0.6, $p=0.006$ ) and OTC drugs and supplements they were currently taking (OR $0.5,95 \% \mathrm{CI} 0.2-0.9, p=0.03$ ). Younger patients and those with inadequate literacy skills were significantly less likely to report telling their doctor about OTC drugs, herbal supplements or vitamins (OTC drugs: $<45$ years old - OR 0.6, 95\% CI $0.3-1.0, p=0.05$; inadequate literacy - OR 0.5 , CI $0.2-0.8, p=0.02$; herbal supplements or vitamins: $<45$ years old - OR $0.6,95 \%$ CI $0.3-0.9, p=0.04$; inadequate literacy - OR 0.6 $95 \%$ CI $0.3-0.9, p=0.02$ ). 
In terms of provider-patient communication outcomes, in multivariable analysis, patients receiving care at academic practices were significantly more likely to report that their physician explained how to take medications (OR 4.8, 95\% CI 1.9-7.5, $p=0.002$ ) or that their physician reviewed their medication list (OR 5.1, 95\% CI 2.8-9.5, $p<0.001$ ) compared to those in safety-net settings. None of the covariates included in the models for pharmacist communication were significant predictors of discussion of proper use or side effects.

\section{Discussion and conclusion}

\subsection{Discussion}

Overall, the findings portray highly prevalent communication failures from all healthcare perspectives we examined. The physician, pharmacist, and patient did not sufficiently assume responsibility for assuring safe medication practices. According to patients, both physicians and pharmacists frequently missed opportunities to counsel them about newly prescribed medications. Despite this apparent lack of counseling, patients often reported not communicating to providers about certain medicines they may be taking regularly, and largely assumed their physicians knew their entire regimen, including those prescribed by other providers and obtained over the counter. These results suggest that patients may perceive a higher degree of integration of medical information than may occur in actual practice. We hypothesize this may be one reason for inadequate medication communication between patients and physicians. This disconnect may result in serious and costly adverse outcomes.

According to patients, medication review was performed less often by physicians and pharmacists. This may reflect a missed opportunity, but could also be attributed to the fact that another member of the clinic staff, such as a medical assistant or nurse, was responsible for this task. Provider discussion of instructions for use was more common, but important communication regarding side effects was low, consistent with previous reports [23,36,37]. The observed differences in patient-reported counseling rates by physicians compared to pharmacists have several possible explanations. First, patients likely received printed drugspecific information leaflets at the point of dispensing as mandated by law; however, these sources of information may have been inadequate for those with limited literacy, which comprised more than half of our study sample. Also, in the community, pharmacy technicians routinely dispense medications and the pharmacist may not be directly involved in counseling in absence of specific patient concerns. Previous studies found that rates of outpatient pharmacist counseling were inversely related to the number of ancillary staff (i.e. technicians) employed in the pharmacy $[22,26]$. Alternatively, patients may have preferred to receive most of their counseling through their physician, although the literature on this is limited [18,37].

In multivariable analyses, younger age and low health literacy were significantly associated with lower rates of reporting regular use of over-the-counter drugs (OTCs), herbal supplements or vitamins to the physician. This supports previous work which has shown that health literacy is associated with the ability to navigate the healthcare system and engage in medical decision-making and self-care $[8,11,38]$. The observed low rates of medication self- 
report among patients with limited literacy highlights the need for providers to be able to identify these individuals and deliver literacy-appropriate communication pertaining to safe, appropriate use. It is also important for providers to ask younger patients (who generally have fewer prescription medications) about routine use of OTCs and supplements as they may not perceive that this is important to disclose.

Patients at academic centers were more likely to believe physicians were aware of their entire medication regimen. Also, patients reported higher rates of side effects discussion and medication list review at academic centers compared to safety-net practices. It is possible that patients at academic centers had easier access to care, shorter waiting times, and longstanding relationships with primary care physicians, thus increasing their perceptions of higher quality. Another possibility is that patients were accurate in their self-report, and that less frequent counseling at community sites was the result of more acute care visits, lower rates of health maintenance encounters, and decreased care continuity. The potential impact of the electronic health record (EHR) on patient beliefs of provider knowledge and communication outcomes was interesting, but warrants further rigorous investigation. It is plausible that an EHR might promote physician-patient communication, but also lead to patients assuming that their physicians are more knowledgeable about prescribed regimens than they actually are.

4.1.1. Limitations-There are several limitations to this study. The primary outcome data relied on self-reports of provider communication rather than observations of actual behavior. We did not record the duration of the office encounters, the provider type (resident, attending physician, or nurse practitioner), or whether the patient was seeing their regular provider the day of the visit; all factors that may have impacted patient beliefs. Information was also not obtained on provider race and cannot establish whether any differences in patient beliefs may have been attributed to race discordance in the patient provider dyad.

Patients were asked about new medications in the past three months and may have recalled lower or higher rates of physician counseling than actually occurred. It is also not clear whether the patient or the provider initiated the conversation about medications. It was not known who was primarily responsible for conducting the medication review in the clinic; this task is routinely performed by nurses or physician's assistants at some clinics. Also, patients may prefer to discuss side effects with physicians more frequently and forgo that type of conversation with pharmacists [37]. It is also possible that some of the noted differences in rates of medication review might be attributed to the use of undisclosed community retail, hospital-based, or mail order pharmacies. Further, among patients with new prescriptions, we did not collect disaggregated data on the specific medications that were prescribed or the types of OTC medications taken and are unable to comment on differences in outcomes by medication type. This study excluded patients that did not speak English, a population that has been shown to have poorer understanding of medication regimens and greater non-adherence $[39,40]$. We also did not examine the direct consequences of the documented communication failures, such as whether lack of provider counseling or patient misbeliefs could result in medication errors, non-adherence to regimens, or adverse clinical outcomes. 
Our exploratory analyses could not definitively isolate the presence of the EHR as the single attributable cause of noted differences in medication review, communication and patient beliefs across study sites. We recognize that there are many additional unmeasured provider, patient, and clinic-level factors that could account for noted differences, and therefore our results should be interpreted with caution. Finally, we did not document the reasons why patients believed their physicians knew their complete regimen and are only able to point out which subgroups held these perceptions more strongly. It will be essential to explore the reasons behind this finding and its implications in further research.

\subsection{Conclusions}

This study is the first to our knowledge to identify a significant gap between patient beliefs of physician awareness of their medication regimen and actual patient reporting of medications to their physician. Patient assumptions about provider knowledge may partly explain the multiple communication deficiencies noted in prior research. Future studies should focus on promoting effective patient-provider communication during the medical encounter. This might include finding opportunities to leverage new resources, such as an EHR, to standardize and provide assurances that these discussions occur and medication lists are reviewed and updated.

\subsection{Practice implications}

Patient assumptions of what physicians know about their regimens and concomitant deficiencies in communication may have serious implications for patient safety and care quality in the ambulatory setting. Clinicians should be mindful to review patients' entire medical regimens and explicitly inquire about medications obtained over the counter or online and those prescribed by other healthcare professionals.

\section{Acknowledgments}

The project was also supported by Award Number T32DK077662 from the National Institute Of Diabetes And Digestive And Kidney Diseases. The content is solely the responsibility of the authors and does not necessarily represent the official views of the National Institute Of Diabetes And Digestive And Kidney Diseases or the National Institutes of Health.

Funding

This project was supported by an unrestricted grant from Target Corporation (PI: Wolf).

\section{References}

1. [November 14th] The Kaiser Family Foundation. Data source: prescription drug trends fact sheet. 2011. May 2010 Update http://www.kff.org/rxdrugs/upload/3057-08.pdf

2. Fortin M, Bravo G, Hudon C, Vanasse A, Lapointe L. Prevalence of multimorbidity among adults seen in family practice. Ann Fam Med. 2005; 3:223-8. [PubMed: 15928225]

3. Wu, S.; Green, A. Projection of chronic illness prevalence and cost inflation. RAND Health; Santa Monica, CA: 2000.

4. Institute of Medicine. To err is human: building a safer health system. Kohn, L.; Corrigan, J.; Donaldson, M., editors. National Academy Press; Washington, DC: 2000.

5. Butler RJ, Davis TK, Johnson WG, Gardner HH. Effects of nonadherence with prescription drugs among older adults. Am J Manag Care. 2011; 17:153-60. [PubMed: 21473664] 
6. Gurwitz JH, Field TS, Harrold LR, Rothschild J, Debellis K, Seger AC, et al. Incidence and preventability of adverse drug events among older persons in the ambulatory setting. J Amer Med Assoc. 2003; 289:1107-16.

7. Osterberg L, Blaschke T. Adherence to medication. N Engl J Med. 2005; 353:487-97. [PubMed: 16079372]

8. Institute of Medicine. Health literacy.. In: Nielsen-Bohlman, L.; Panzer, A.; Kindig, DA., editors. A prescription to end confusion. National Academy Press; Washington, DC: 2004.

9. Davis TC, Wolf MS, Bass PF 3rd, Middlebrooks M, Kennen E, Baker DW, et al. Low literacy impairs comprehension of prescription drug warning labels. J Gen Intern Med. 2006; 21:847-51. [PubMed: 16881945]

10. Davis TC, Wolf MS, Bass PF 3rd, Thompson JA, Tilson HH, Neuberger M, et al. Literacy and misunderstanding prescription drug labels. Ann Intern Med. 2006; 145:887-94. [PubMed: 17135578]

11. Persell SD, Osborn CY, Richard R, Skripkauskas S, Wolf MS. Limited health literacy is a barrier to medication reconciliation in ambulatory care. J Gen Intern Med. 2007; 22:1523-6. [PubMed: 17786521]

12. Wilson IB, Schoen C, Neuman P, Strollo MK, Rogers WH, Chang H, et al. Physician-patient communication about prescription medication nonadherence: a 50-state study of America's seniors. J Gen Intern Med. 2007; 22:6-12. [PubMed: 17351835]

13. Wolf MS, Davis TC, Tilson HH, Bass PF 3rd, Parker RM. Misunderstanding of prescription drug warning labels among patients with low literacy. Am J Health Syst Pharm. 2006; 63:1048-55. [PubMed: 16709891]

14. Mehta DH, Gardiner PM, Phillips RS, McCarthy EP. Herbal and dietary supplement disclosure to health care providers by individuals with chronic conditions. J Altern Complement Med. 2008; 14:1263-9. [PubMed: 19032071]

15. Sleath B, Roter D, Chewning B, Svarstad B. Asking questions about medication: analysis of physician-patient interactions and physician perceptions. Med Care. 1999; 37:1169-73. [PubMed: 10549619]

16. Sleath B, Rubin RH, Campbell W, Gwyther L, Clark T. Ethnicity and physician-older patient communication about alternative therapies. J Altern Complement Med. 2001; 7:329-35. [PubMed: 11558775]

17. Stevenson FA, Barry CA, Britten N, Barber N, Bradley CP. Doctor-patient communication about drugs: the evidence for shared decision making. Soc Sci Med. 2000; 50:829-40. [PubMed: 10695980]

18. Stevenson FA, Cox K, Britten N, Dundar Y. A systematic review of the research on communication between patients and health care professionals about medicines: the consequences for concordance. Health Expect. 2004; 7:235-45. [PubMed: 15327462]

19. Richard C, Lussier MT. Nature and frequency of exchanges on medications during primary care encounters. Patient Educ Couns. 2006; 64:207-16. [PubMed: 16781108]

20. Richard C, Lussier MT. Measuring patient and physician participation in exchanges on medications: dialogue ratio, preponderance of initiative, and dialogical roles. Patient Educ Couns. 2007; 65:329-41. [PubMed: 17095179]

21. Mahler C, Jank S, Hermann K, Haefeli WE, Szecsenyi J. Information on medications - how do chronically ill patients assess counselling on drugs in general practice? Dtsch Med Wochenschr. 2009; 134:1620-4. [PubMed: 19650022]

22. Dickson WM, Rodowskas CA Jr. Verbal communications of community pharmacists. Med Care. 1975; 13:486-98. [PubMed: 1142855]

23. Carter BL, Ardery G, Dawson JD, James PA, Bergus GR, Doucette WR, et al. Physician and pharmacist collaboration to improve blood pressure control. Arch Intern Med. 2009; 169:19962002. [PubMed: 19933962]

24. Fern FH. New pharmacy mandates and practice standards now taking effect under OBRA'90 deadline. Healthspan. 1993; 10:12-4. [PubMed: 10125342]

25. Flynn EA, Barker KN, Berger BA, Lloyd KB, Brackett PD. Dispensing errors and counseling quality in 100 pharmacies. J Am Pharm Assoc (2003). 2009; 49:171-80. [PubMed: 19289343] 
26. Kimberlin CL, Jamison AN, Linden S, Winterstein AG. Patient counseling practices in U.S. pharmacies: effects of having pharmacists hand the medication to the patient and state regulations on pharmacist counseling. J Am Pharm Assoc (2003). 2011; 51:527-34. [PubMed: 21752776]

27. McLean DL, McAlister FA, Johnson JA, King KM, Makowsky MJ, Jones CA, et al. A randomized trial of the effect of community pharmacist and nurse care on improving blood pressure management in patients with diabetes mellitus: study of cardiovascular risk intervention by pharmacists-hypertension (SCRIP-HTN). Arch Intern Med. 2008; 168:2355-61. [PubMed: 19029501]

28. Nkansah N, Mostovetsky O, Yu C, Chheng T, Beney J, Bond CM, et al. Effect of outpatient pharmacists' non-dispensing roles on patient outcomes and prescribing patterns. CDS Rev. 2010:CD000336.

29. Committee on Quality of Health Care in America, Institute of Medicine. Crossing the quality chasm: a new health system for the 21st century. National Academy Press; Washington, DC: 2001.

30. Nassaralla CL, Naessens JM, Hunt VL, Bhagra A, Chaudhry R, Hansen MA, et al. Medication reconciliation in ambulatory care: attempts at improvement. Qual Saf Health Care. 2009; 18:4027. [PubMed: 19812105]

31. Orrico KB. Sources and types of discrepancies between electronic medical records and actual outpatient medication use. J Manag Care Pharm. 2008; 14:626-31. [PubMed: 18774872]

32. Jena AB, Goldman DP, Foster SE, Califano JA Jr. Prescription medication abuse and illegitimate internet-based pharmacies. Ann Intern Med. 2011; 155:848-50. [PubMed: 22184692]

33. Jena AB, Goldman DP. Growing Internet use may help explain the rise in prescription drug abuse in the United States. Health affairs. 2011; 30:1192-9. [PubMed: 21565838]

34. American Association for Public Opinion Research. Standard definitions: final dispositions of case codes and outcomes rates for surveys. 3rd ed.. American Association for Public Opinion Research; Lenexa, KS: 2004.

35. Davis TC, Long SW, Jackson RH, Mayeaux EJ, George RB, Murphy PW, et al. Rapid estimate of adult literacy in medicine: a shortened screening instrument. Fam Med. 1993; 25:391-5. [PubMed: 8349060]

36. Svarstad BL, Bultman DC, Mount JK. Patient counseling provided in community pharmacies: effects of state regulation, pharmacist age, and busyness. J Am Pharm Assoc (2003). 2004; 44:229. [PubMed: 14965149]

37. Tarn DM, Heritage J, Paterniti DA, Hays RD, Kravitz RL, Wenger NS. Physician communication when prescribing new medications. Arch Intern Med. 2006; 166:1855-62. [PubMed: 17000942]

38. Persell SD, Bailey SC, Tang J, Davis TC, Wolf MS. Medication reconciliation and hypertension control. Am J Med. 2010; 123:182, e9-e15. [PubMed: 20103029]

39. Wilson E, Chen AH, Grumbach K, Wang F, Fernandez A. Effects of limited English proficiency and physician language on health care comprehension. J Gen Intern Med. 2005; 20:800-6. [PubMed: 16117746]

40. Westberg SM, Sorensen TD. Pharmacy-related health disparities experienced by non-englishspeaking patients: impact of pharmaceutical care. J Am Pharm Assoc (2003). 2005; 45:48-54. [PubMed: 15730117] 


\section{Table 1}

Sample characteristics.

\begin{tabular}{|c|c|c|}
\hline Variables & All patients $(n=500)$ & Patients with recent prescription $(n=190)$ \\
\hline Age, mean (SD) & $48.9(14.4)$ & $48.0(14.2)$ \\
\hline Male, $\%$ & 39.6 & 35.1 \\
\hline \multicolumn{3}{|l|}{ Race, $\%$} \\
\hline Black & 63.6 & 58.4 \\
\hline White & 32.8 & 36.8 \\
\hline Other & 3.6 & 4.8 \\
\hline \multicolumn{3}{|l|}{ Years of education, $\%$} \\
\hline$<$ High school & 19.4 & 22.0 \\
\hline High school & 33.2 & 31.3 \\
\hline Some college & 20.4 & 20.9 \\
\hline College graduate & 26.6 & 25.8 \\
\hline \multicolumn{3}{|l|}{ Literacy level, $\%$} \\
\hline Inadequate ( $\$$ th grade) & 20.9 & 19.5 \\
\hline Marginal (7th-8th grade) & 31.6 & 26.5 \\
\hline Adequate ( $\otimes 9$ th grade) & 47.5 & 54.0 \\
\hline Medications taken daily, mean (SD) & $2.9(3.1)$ & $4.0(3.6)$ \\
\hline \multicolumn{3}{|l|}{ Number of prescribing physicians } \\
\hline 0 & $11.4^{*}$ & $1.6^{* *}$ \\
\hline 1 & 65.6 & 67.0 \\
\hline 2 & 16.3 & 20.5 \\
\hline
\end{tabular}

* 56 patients reported having no prescription medications.

** 3 patients with recent prescription reported not having a regularly prescribing physician. 


\section{Table 2}

Prevalence of patient-reported beliefs about provider medication awareness and medication-related providerpatient communication.

\begin{tabular}{lc}
\hline Item & Total, \% \\
\hline Patient beliefs about provider medication awareness $(n=500)$ & \\
Doctor is aware of all medicines I am taking & 90.2 \\
Doctor is aware of all OTC drugs I am taking & 85.4 \\
Doctor is aware of medicines prescribed by other doctors & 91.3 \\
Patient-reported rates of medication-related communications patient communication $(n=500)$ & \\
Told doctor about OTC drugs currently taking & 46.0 \\
Told doctor about herbal supplements or vitamins currently taking & 34.1 \\
Physician communication $(n=190)$ & \\
Reviewed medication list & 51.3 \\
Explained how to take medicine & 77.4 \\
Described side effects & 42.9 \\
Pharmacist communication $(n=190)$ & \\
Explained how to take medicine & 43.3 \\
Described side effects & 25.8 \\
\hline
\end{tabular}




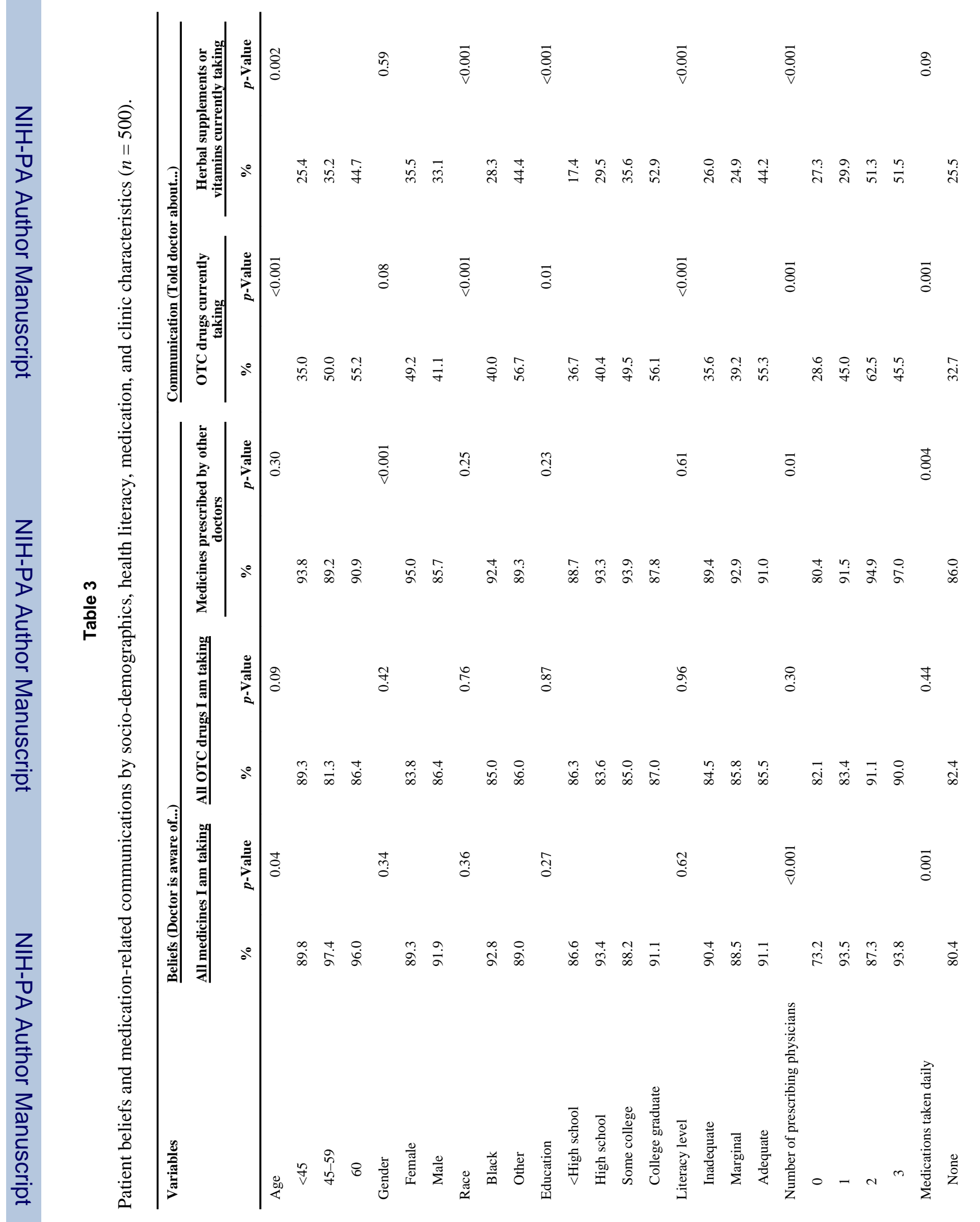




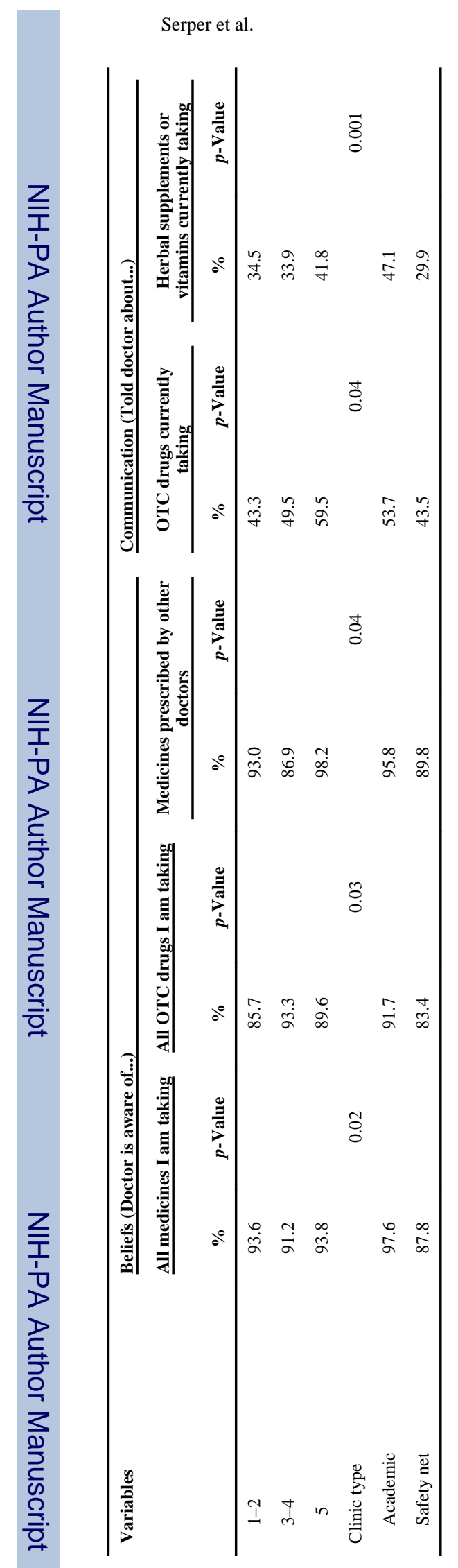

Patient Educ Couns. Author manuscript; available in PMC 2014 November 01. 


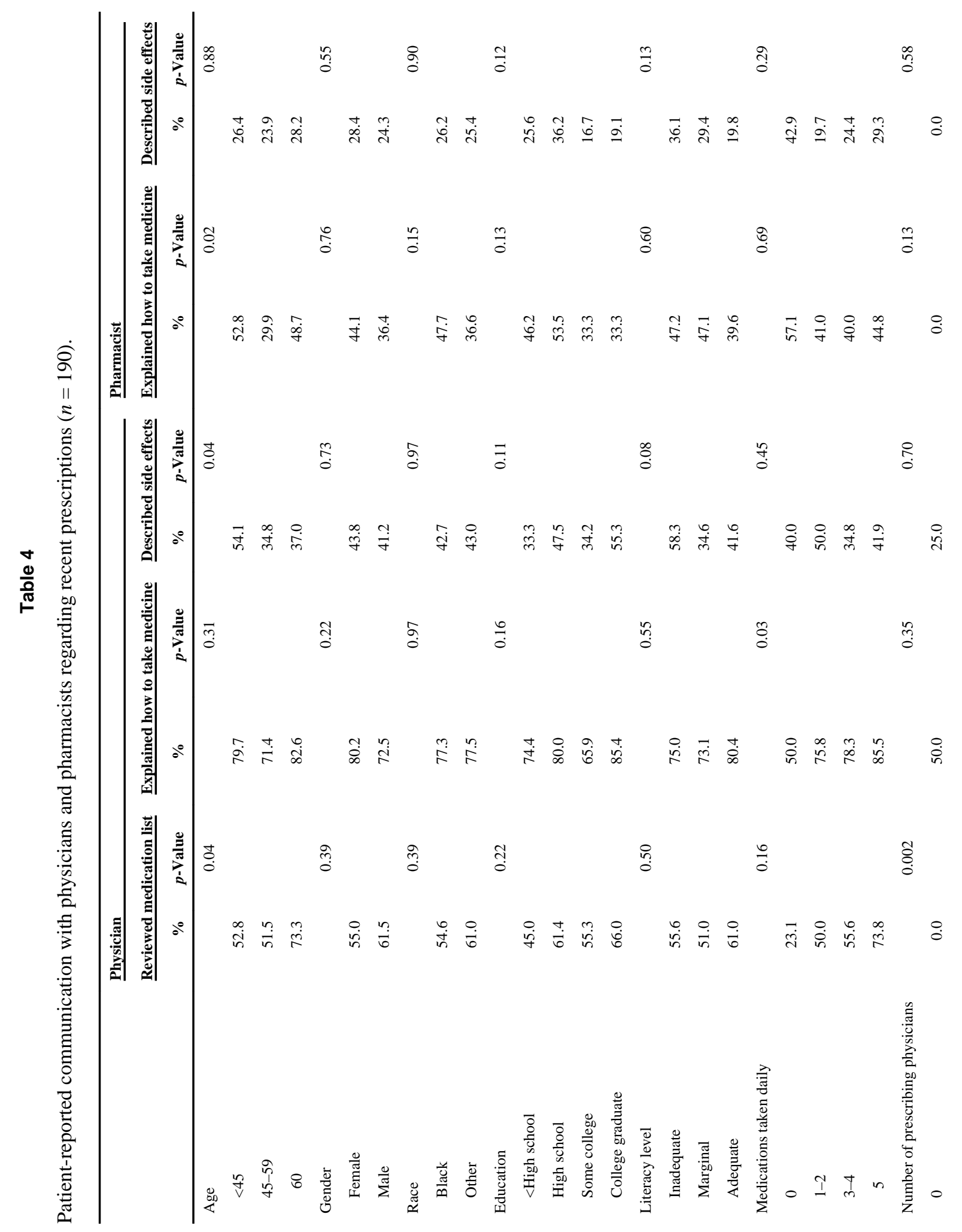

Patient Educ Couns. Author manuscript; available in PMC 2014 November 01. 


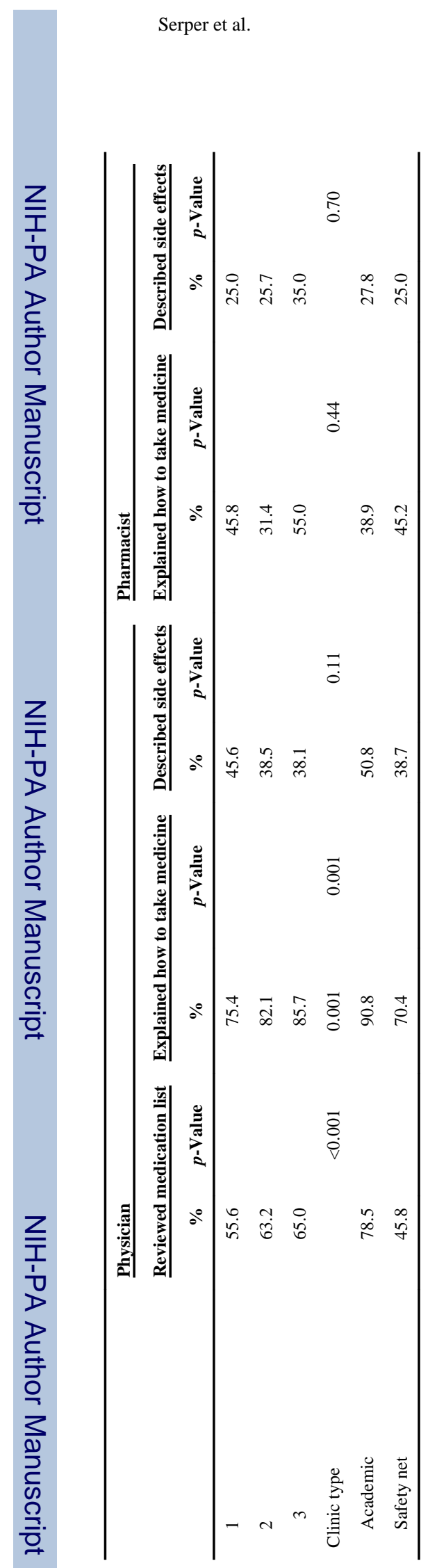

Page 16 